OPEN ACCESS

Edited by:

Mehdi Mirsaeidi,

University of Miami, United States

Reviewed by:

Spyros Papiris,

National and Kapodistrian University

of Athens, Greece

Bernadette Gochuico,

National Human Genome Research

Institute (NHGRI), United States

*Correspondence:

Sachin Chaudhary

sachin@deptofmed.arizona.edu

Specialty section:

This article was submitted to

Pulmonary Medicine,

a section of the journal

Frontiers in Medicine

Received: 29 June 2020

Accepted: 30 July 2020

Published: 09 September 2020

Citation:

Chaudhary S, Natt B, Bime C, Knox KS and Glassberg MK (2020)

Antifibrotics in COVID-19 Lung

Disease: Let Us Stay Focused.

Front. Med. 7:539

doi: 10.3389/fmed.2020.00539

\section{Antifibrotics in COVID-19 Lung Disease: Let Us Stay Focused}

\author{
Sachin Chaudhary ${ }^{1 *}$, Bhupinder Natt ${ }^{1}$, Christian Bime ${ }^{1}$, Kenneth S. Knox ${ }^{2}$ and \\ Marilyn K. Glassberg ${ }^{2}$
}

1 Interstitial Lung Disease Program, University of Arizona Colleges of Medicine, Tucson, AZ, United States, ${ }^{2}$ Banner-University Medicine Division, Phoenix, AZ, United States

After decades of research, two therapies for chronic fibrotic lung disease are now approved by the FDA, with dozens more anti-fibrotic therapies in the pipeline. A great deal of enthusiasm has been generated for the use of these drugs, which are by no means curative but clearly have a favorable impact on lung function decline over time. Amidst a flurry of newly developed and repurposed drugs to treat the coronavirus disease 2019 (COVID-19) and its accompanying acute respiratory distress syndrome (ARDS), few have emerged as effective. Historically, survivors of severe viral pneumonia and related acute lung injury with ARDS often have near full recovery of lung function. While the pathological findings of the lungs of patients with COVID-19 can be diverse, current reports have shown significant lung fibrosis predominantly in autopsy studies. There is growing enthusiasm to study anti-fibrotic therapy for inevitable lung fibrosis, and clinical trials are underway using currently FDA-approved anti-fibrotic therapies. Given the relatively favorable outcomes of survivors of virus-mediated ARDS and the low prevalence of clinically meaningful lung fibrosis in survivors, this perspective examines if there is a rationale for testing these repurposed antifibrotic agents in COVID-19-associated lung disease.

\section{Keywords: antifibrotics, COVID - 19, ARDS, fibrosis, SARS - CoV-2, SARS, MERS (Middle East respiratory syndrome)}

\section{INTRODUCTION}

The coronavirus 2 (SARS-CoV-2)-driven coronavirus disease 2019 (COVID-19) pandemic and its deadliest complication, acute respiratory distress syndrome (ARDS), have fundamentally changed our world. Clinicians are piecing together the puzzle that is COVID-19. Information on disease pathogenesis and possible therapies surfaced initially, much out of necessity, from social media, listservs, case reports, and non-peer reviewed observations. Now, months since the initial description in Wuhan, China, with almost 10 million infected worldwide and about half a million deaths, the clinical and the scientific communities have learned much and pivoted to high-quality evidence for the management of COVID-19 patients. Strong scientific rationale must be articulated before approaching critically ill, consent-weary patients and their families to enroll in clinical trials (1). Along the way, there have been a few missteps. A recent review has shed light on the potentially dangerous treatment decisions when equating ARDS seen in COVID19 infection to the mechanistically distinct physiology of high-altitude pulmonary edema (2). Despite robust in vitro mechanistic rationale, hydroxychloroquine has failed to protect against respiratory viruses in previous studies (3) and yet again has not proven effective in COVID-19 $(4,5)$. Among the many excellent ongoing studies with good preclinical data in appropriate 
animal models, some arising directly from recent clinical observations, we were surprised to see studies proposing to use the FDA-approved anti-fibrotic therapies (nintedanib NCT04338802 and pirfenidone NCT04282902) for idiopathic pulmonary fibrosis (IPF) in COVID-19 patients. We acknowledge that some patients with severe, prolonged viral pneumonia and ARDS will die as a consequence of inflammation-induced fibrosis. We also recognize that clinical and experimental data suggest overlapping mechanistic pathways with inflammatory scar and IPF $(6,7)$. The survivors of ARDS, regardless of cause, clearly have important long-term limitations. Muscle weakness, exercise limitation, physical and psychological sequelae, and decreased physical quality of life are well known (8). However, lung function upon recovery is often normal or well preserved and improves over time (9), arguing against a need for fibrosis-preventive therapies. Therefore, COVID-19associated lung fibrosis does not seem to be the next phase of this pandemic requiring preventive or curative interventions (10). In this review, we posit that, unlike patients with IPF, the COVID19 survivors will follow a familiar course of intense pulmonary inflammation, leading to mild scarring and near-normal lung function recovery over time.

\section{CHRONIC PROGRESSIVE LUNG FIBROSIS IS NOT A FEATURE AMONG SURVIVORS OF ARDS}

ARDS is a form of severe acute lung injury characterized by its acute onset, bilateral pulmonary infiltrates, severe hypoxemia, and noncardiac pulmonary edema. In most cases, this is accompanied by intense neutrophilic alveolitis (11). Mechanical ventilation is needed as supportive therapy for patients with ARDS and can perpetuate lung injury (12). ARDS is also characterized pathologically by an initial exudative and inflammatory phase, followed by a fibroproliferative phase and, in non-survivors, end-stage fibrotic lung. With supportive measures, including low-tidal-volume ventilation, to minimize ventilator-induced lung injury and fibrosis, ARDS outcomes are improved (13). Cabrera-Benitez describes a "fibrosis paradox," where those patients who die of ARDS had a prolonged course and evidence of pulmonary fibrosis. In contrast, ARDS survivors have relatively little evidence of fibrosis when biomarker measurement, lung function testing, or imaging is performed (14).

Fibrosis on biopsy correlated with poor outcome in a diverse ARDS cohort, but most patients had mild to no fibrosis (15). In an autopsy study of ARDS, fibrosis was noted in $4 \%$ of patients with disease of $<1$ week in duration, $24 \%$ of patients with disease of 1-3 weeks in duration, and 14 of 23 patients with disease lasting longer than 3 weeks. Fibrosis was more frequent in ARDS of pulmonary origin than that of extrapulmonary origin (16). Nevertheless, survivors of ARDS have a favorable pulmonary prognosis. In one study, forced expiratory volume in the first second (FEV1), forced vital capacity (FVC), and lung diffusing capacity for carbon monoxide (DLCO) were mildly reduced, with $>80 \%$ of survivors showing normal or mild abnormalities on chest imaging at 6-month follow-up (17). Herridge et al. followed patients for 5 years and noted normal or near-normal volumetric and spirometric test results by 5 years. The results of the 6min walk tests were near normal. The most common finding in patients who had a chest CT available was minor, nondependent pulmonary fibrotic changes (9). Many of the studies enrolled patients at a time when low-tidal-volume ventilation, perhaps the best therapy available for preventing and treating ARDS, was in its early stages of being consistently employed in intensive care unit (ICU) care.

\section{INFLUENZA-INDUCED ARDS}

The majority of ARDS studies include a heterogeneous patient population in which the onset and the etiology of ARDS are ill defined. In contrast, the onset of a viral illness and its course are often known. Clinical, physiological, and radiological follow-up studies of patients with ARDS have been conducted in previous viral pandemics. Although it is difficult to tease out ARDS patients from ICU patients with severe viral pneumonias in the literature, studies of patients with ARDS due to influenza H1N1 and H7N9 strains have shown that, although functional impairment occurs, residual spirometric and radiological abnormalities are often inconsequential clinically, with evidence of distortion of septal lines, parenchymal bands, and bronchiectasis. Pulmonary function inevitably improves over time $(18,19)$. In some studies, mild diffusing abnormalities persist in ARDS patients despite the normalization of FEV1 and FVC (20).

\section{ARDS INDUCED BY MERS AND SARS}

COVID-19, like other novel coronaviruses-severe acute respiratory syndrome (SARS, 2002 to 2004), Middle East respiratory syndrome (MERS, 2012-2015) - is associated with high mortality from ARDS and multi-organ system failure. Fewer studies are available for outcomes in MERS, but similar to other causes of viral-induced lung injury, MERS survivors have a reduced quality of life (21), and the pulmonary sequelae from MERS are mild. In a cohort of less severely ill MERS pneumonia patients, only the subgroup with severe pneumonia showed an abnormal mean diffusing capacity, which was mildly reduced at $68 \%$ of predicted normal (22). In a study of 36 patients with a median follow-up time of 43 days, the follow-up chest radiographs were normal in $64 \%$ of patients. Those with lung scarring (23) of varying degrees were older, and no patients were followed for 1 year to determine if those with acute findings had improved over time. In a few case reports of patients who died of MERS, the predominant finding at autopsy was diffuse alveolar damage (24).

Several longitudinal studies have examined the long-term outcomes in SARS survivors. It is estimated that up to $36 \%$ of patients with SARS required ICU admission, with $26 \%$ meeting the criteria for ARDS. These patients have a significant impairment in health status at 1 year, which 
show modest correlations but are out of proportion to nearnormal pulmonary function. Less than $4 \%$ of patients had severely reduced DLCO, and none were hypoxemic on the 6 -min walk test $(25,26)$. In a study by Xie et al., $20 \%$ of SARS survivors had residual radiographic abnormalities on follow-up. The findings included interstitial thickening, groundglass opacification, bronchiectasis, and signs of volume loss. Forty patients underwent high-resolution computed tomography imaging examination after approximately 1 month, with over half of them showing an improvement (27). In another study, the predominant CT findings were air trapping and groundglass opacities in $90 \%$ of patients. Reticulation and parenchymal bands were also common, followed by bronchiectasis in $20 \%$ of patients and honeycombing in one patient. In the subgroup of patients with ARDS, the ground-glass and interstitial opacity scores decreased significantly, although there was no significant change in air trapping at 4 to 5 months (28). In survivors of SARS followed for 15 years, pulmonary interstitial damage and functional decline caused by SARS mostly recovered within 2 years after rehabilitation (29). The histopathology of SARS has been extensively reviewed in autopsy series with limited information in SARS survivors. The lungs in SARS predominantly show diffuse alveolar damage and follow similar injury patterns, as seen in ARDS of other causes, with hyaline membranes and fibrinous tissue in alveolar spaces. The extent of fibrous organization correlates with the length of the disease. Active pulmonary injury, however, can be seen for months, and fibrin balls within airspaces with features of organizing pneumonia are unique (30).

\section{COVID-19 ARDS}

Although it is too early to reliably define the long-term outcomes in patients recovering from a severe COVID-19 infection, patients with severe pneumonia have near-normal spirometry and moderate decreases in diffusing capacity (31). Radiographically, the viral lung injury shows patterns similar to SARS, with some patients developing predominant ground glass infiltrates evolving to linear bands and architectural distortion (32). COVID-19 is unique in that ARDS can be atypical, with severe hypoxemia at times being associated with near-normal respiratory system compliance in some patients. Despite sharing the same viral etiology, these severely hypoxemic patients may present quite differently, thus requiring different management algorithms (33). Even as these subtypes are being identified and histopathological studies are emerging, the exact mechanism of lung injury in COVID-19 remains unclear.

Autopsy data are now available from multiple centers. Common findings emerge from these reports, including DAD (the histopathological correlate of ARDS) at different stages in all patients (34). Thickened alveolar septa with perivascular lymphocytic-plasmocytic infiltration are common and reflect a viral etiology of ARDS. There are also novel findings showing enhanced microthrombi, endothelialitis, and vascular involvement in COVID-19 as compared to other etiologies of ARDS $(35,36)$. Until recently, one finding that has lacked emphasis, frequency, and consistency in these reports is pulmonary fibrosis. A recent systematic review by Polak et al. summarizes the pathological findings from both autopsy and biopsy reports. In lung samples from 131 patients, 17 were ante-mortem, including three lung transplant explants. The majority of these 17 patients did not survive to be discharged from the hospital. The histological patterns identified in the cohort were reactive epithelial changes with DAD in $85 \%$ and microvascular damage with microthrombi and organizing pneumonia in 59\%. The fibrotic pattern was seen in $22 \%$ and occurred approximately 3 weeks after the illness, with $7 \%$ showing some evidence of microcystic honeycombing (37). Although it is clearly too early to comment on the longterm functional outcomes in COVID-19 patients, a personalized approach given the unique pathologic findings, physiology, and phenotypes is warranted (38). Nevertheless, we speculate that the lung function deficits will improve as recovery ensues and that survivors who develop lung scarring, much like other viral etiologies of ARDS, will overwhelmingly have minimal pulmonary physiological consequences.

\section{PUTTING SCARRING AND LUNG FIBROSIS INTO CONTEXT}

Our perspective is that the survivors of post-viral ARDS recover with mild residual pulmonary deficits and that interventions to prevent these mild abnormalities are unnecessary during the COVID-19 pandemic. Despite overlapping pathways, the timing, etiology, prognosis, and mechanistic underpinnings of post-viral scarring are quite different than chronic fibrosing interstitial lung disease. IPF is progressive and eventually fatal in most patients (39). Pulmonary fibrosis secondary to autoimmune causes such as rheumatoid arthritis and scleroderma may similarly progress and can be treated with an approved anti-fibrotic therapy. Patients with connective tissue diseases who develop lung fibrosis have a relatively poor prognosis (40). In contrast, while postinflammatory changes can be seen in some ARDS survivors, progressive fibrosis has not been an important characteristic in ARDS related to respiratory infections and viral pneumonias.

Our recent understanding of the pauci-immune mechanism of IPF differs substantially from the intense inflammatory response noted in ARDS and viral pneumonias. Moreover, viral inflammation induces robust $\mathrm{T}$ cell responses that can persist for months (41). It is quite possible that a significant subset of patients with COVID-19 have ARDS physiology (or atypical ARDS with relatively normal lung compliance) due to highintensity lymphocytic alveolitis. This contrasts with other causes of ARDS in which an intense neutrophilic alveolitis is the rule. Comparisons have been made between ARDS-related fibrosis in humans and the intense inflammation and scarring in the bleomycin mouse model, a model in which young mice resolve their fibrotic lung disease (42). Age and underlying lung diseases may be important risk factors for enhanced fibrotic responses following ARDS. In the late stages of ARDS, diffuse alveolar damage with excessive and abnormal deposition of extracellular collagen matrix predominates as a consequence of the known 
acute inflammatory insult. Interstitial and intra-alveolar fibrosis is often noted to varying degrees. The elevated levels of NTPCP-III, which is derived from the cleavage of procollagen III, may be a useful biomarker to stratify therapies in critically ill patients with different phenotypes (43). Fibrosis from ARDS, in contrast to IPF, does not progress nor lead to a dominant pattern of honeycombing. Although the etiology of IPF remains obscure, the pathogenesis is best understood as a consequence of repetitive injuries followed by dysregulated repair processes, facilitated by telomere shortening, not intense inflammation (4446).

\section{DISCUSSION}

An excellent and thought-provoking review by George et al. highlights many nuances related to the care of IPF patients in the context of COVID-19 (7). Caring for patients with an underlying fibrotic lung disease is complex. The currently available antifibrotics have pleiotropic effects, allowing for many hypotheses related to their potential utility in other disease processes. It is clear that studies will proliferate as commercial interests grow and the pandemic continues in the absence of effective anti-virals and vaccines. The currently approved anti-fibrotics are meant for chronic disease management and by no means are curative nor do they reverse fibrosis. As such, despite the enthusiasm

\section{REFERENCES}

1. Caulfield T. Pseudoscience and COVID-19 - we've had enough already. Nature. (2020). doi: 10.1038/d41586-020-01266-z. [Epub ahead of print].

2. Luks AM, Swenson ER. COVID-19 lung injury and high altitude pulmonary edema: a false equation with dangerous implications. Ann Am Thorac Soc. (2020) 17:918-21. doi: 10.1513/AnnalsATS.202004-327FR

3. Paton NI, Lee L, Xu Y, Ooi EE, Cheung YB, Archuleta S, et al. Chloroquine for influenza prevention: a randomised, double-blind, placebo controlled trial. Lancet Infect Dis. (2011) 11:677-83. doi: 10.1016/S1473-3099(11) 70065-2

4. Geleris J, Sun Y, Platt J, Zucker J, Baldwin M, Hripcsak G, et al. Observational study of hydroxychloroquine in hospitalized patients with Covid-19. $\mathrm{N} \mathrm{Engl} \mathrm{J}$ Med. (2020) 382:2411-18. doi: 10.1056/NEJMoa2012410

5. Boulware DR, Pullen MF, Bangdiwala AS, Pastick KA, Lofgren SM, Okafor EC, et al. A randomized trial of hydroxychloroquine as postexposure prophylaxis for Covid-19. N Engl J Med. (2020) 383:517-25. doi: 10.1056/NEJMoa20 16638

6. Venkataraman T, Frieman MB. The role of epidermal growth factor receptor (EGFR) signaling in SARS coronavirus-induced pulmonary fibrosis. Antiviral Res. (2017) 143:142-50. doi: 10.1016/j.antiviral.2017.03.022

7. George PM, Wells AU, Jenkins RG. Pulmonary fibrosis and COVID-19: the potential role for antifibrotic therapy. Lancet Respir Med. (2020) 8:80715. doi: 10.1016/S2213-2600(20)30225-3

8. Bein T, Weber-Carstens S, Apfelbacher C. Long-term outcome after the acute respiratory distress syndrome: different from general critical illness? Curr Opin Crit Care. (2018) 24:35-40. doi: 10.1097/MCC.0000000000000476

9. Herridge MS, Tansey CM, Matte A, Tomlinson G, Diaz-Granados N, Cooper A, et al. Canadian critical care trials, functional disability 5 years after acute respiratory distress syndrome. N Engl J Med. (2011) 364:1293304. doi: 10.1056/NEJMoa1011802

10. Spagnolo P, Balestro E, Aliberti S, Cocconcelli E, Biondini D, Casa GD, et al. Pulmonary fibrosis secondary to COVID-19: a call to arms? Lancet Respir Med. (2020) 8:750-2. doi: 10.1016/S2213-2600(20)30222-8 to study these medications, we believe that there is insufficient scientific rationale to do so, given the favorable course and the low prevalence of clinically meaningful scarring in survivors.

The number of patients suffering from COVID-19 is accumulating and will be millions worldwide. Certainly we must evaluate patients, prospectively and retrospectively, to define the scope and the burden of residual pulmonary deficits and the fibrotic changes to determine their clinical significance. However, we find ourselves asking: Is it worth spending valuable time, resources, and scientific energy studying anti-fibrotic therapies in acutely ill, consent-weary patients that truly need a targeted antiviral treatment or trial? The responsible answer is "no." Let us keep our focus during the pandemic.

\section{DATA AVAILABILITY STATEMENT}

The raw data supporting the conclusions of this article will be made available by the authors, without undue reservation.

\section{AUTHOR CONTRIBUTIONS}

All authors have contributed to the conception and design of the work, were involved in drafting and revising the content, gave final approval of the version to be published, and agree to be accountable for the integrity and all aspects of the work.
11. Piantadosi CA, Schwartz DA. The acute respiratory distress syndrome. Ann Intern Med. (2004) 141:46070. doi: 10.7326/0003-4819-141-6-200409210-00012

12. Slutsky AS, Ranieri VM. Ventilator-induced lung injury. N Engl J Med. (2013) 369:2126-36. doi: 10.1056/NEJMra1208707

13. Acute Respiratory Distress Syndrome Network, Brower RG, Matthay MA, Morris A, Schoenfeld D, Thompson BT, et al. Ventilation with lower tidal volumes as compared with traditional tidal volumes for acute lung injury and the acute respiratory distress syndrome. $N$ Engl J Med. (2000) 342:1301-8. doi: 10.1056/NEJM200005043 421801

14. Cabrera-Benitez NE, Laffey JG, Parotto M, Spieth PM, Villar J, Zhang H, et al. Mechanical ventilation-associated lung fibrosis in acute respiratory distress syndrome: a significant contributor to poor outcome. Anesthesiology. (2014) 121:189-98. doi: 10.1097/ALN.0000000000000264

15. Martin C, Papazian L, Payan MJ, Saux P, Gouin F. Pulmonary fibrosis correlates with outcome in adult respiratory distress syndrome. A study in mechanically ventilated patients. Chest. (1995) 107:196-200. doi: 10.1378/chest.107.1.196

16. Thille AW, Esteban A, Fernandez-Segoviano P, Rodriguez JM, Aramburu JA, Vargas-Errazuriz P, et al. Chronology of histological lesions in acute respiratory distress syndrome with diffuse alveolar damage: a prospective cohort study of clinical autopsies. Lancet Respir Med. (2013) 1:395401. doi: 10.1016/S2213-2600(13)70053-5

17. Masclans JR, Roca O, Munoz X, Pallisa E, Torres F, Rello J, et al. Quality of life, pulmonary function, and tomographic scan abnormalities after ARDS. Chest. (2011) 139:1340-6. doi: 10.1378/chest.10-2438

18. Chen J, Wu J, Hao S, Yang M, Lu X, Chen X, et al. Long term outcomes in survivors of epidemic Influenza A (H7N9) virus infection. Sci Rep. (2017) 7:17275. doi: 10.1038/s41598-017-17497-6

19. Mineo G, Ciccarese F, Modolon C, Landini MP, Valentino M, Zompatori M. Post-ARDS pulmonary fibrosis in patients with H1N1 pneumonia: role of follow-up CT. Radiol Med. (2012) 117:185-200. doi: 10.1007/s11547-011-0740-3 
20. Luyt CE, Combes A, Becquemin MH, Beigelman-Aubry C, Hatem S, Brun AL, et al. Long-term outcomes of pandemic 2009 influenza A(H1N1)-associated severe ARDS. Chest. (2012) 142:583-92. doi: 10.1378/chest.11-2196

21. Batawi S, Tarazan N, Al-Raddadi R, Al Qasim E, Sindi A, Al Johni S, et al. Quality of life reported by survivors after hospitalization for Middle East respiratory syndrome (MERS). Health Qual Life Outcomes. (2019) 17:101. doi: 10.1186/s12955-019-1165-2

22. Park WB, Jun KI, Kim G, Choi JP, Rhee JY, Cheon S, et al. Correlation between pneumonia severity and pulmonary complications in middle east respiratory syndrome. J Korean Med Sci. (2018) 33:e169. doi: 10.3346/jkms.2018.33.e169

23. Das KM, Lee EY, Singh R, Enani MA, Al Dossari K, Van Gorkom $\mathrm{K}$, et al. Follow-up chest radiographic findings in patients with MERS-CoV after recovery. Indian $J$ Radiol Imaging. (2017) 27:342-9. doi: 10.4103/ijri.IJRI_469_16

24. Alsaad KO, Hajeer AH, Al Balwi M, Al Moaiqel M, Al Oudah N, Al Ajlan A, et al. Histopathology of Middle East respiratory syndrome coronovirus (MERS-CoV) infection - clinicopathological and ultrastructural study. Histopathology. (2018) 72:516-24. doi: 10.1111/his.13379

25. Hui DS, Wong KT, Ko FW, Tam LS, Chan DP, Woo J, et al. The 1-year impact of severe acute respiratory syndrome on pulmonary function, exercise capacity, and quality of life in a cohort of survivors. Chest. (2005) 128:224761. doi: 10.1378/chest.128.4.2247

26. Ngai JC, Ko FW, Ng SS, To KW, Tong M, Hui DS. The longterm impact of severe acute respiratory syndrome on pulmonary function, exercise capacity and health status. Respirology. (2010) 15:543-50. doi: 10.1111/j.1440-1843.2010.01720.x

27. Xie L, Liu Y, Xiao Y, Tian Q, Fan B, Zhao H, et al. Follow-up study on pulmonary function and lung radiographic changes in rehabilitating severe acute respiratory syndrome patients after discharge. Chest. (2005) 127:211924. doi: 10.1378/chest.127.6.2119

28. Chang YC, Yu CJ, Chang SC, Galvin JR, Liu HM, Hsiao CH, et al. Pulmonary sequelae in convalescent patients after severe acute respiratory syndrome: evaluation with thin-section CT. Radiology. (2005) 236:106775. doi: $10.1148 /$ radiol. 2363040958

29. Zhang P, Li J, Liu H, Han N, Ju J, Kou Y, et al. Long-term bone and lung consequences associated with hospital-acquired severe acute respiratory syndrome: a 15-year follow-up from a prospective cohort study. Bone Res. (2020) 8:8. doi: 10.1038/s41413-020-0084-5

30. Gu J, Korteweg C. Pathology and pathogenesis of severe acute respiratory syndrome. Am J Pathol. (2007) 170:1136-47. doi: 10.2353/ajpath.2007.061088

31. Mo X, Jian W, Su Z, Chen M, Peng H, Peng P, et al. Abnormal pulmonary function in COVID-19 patients at time of hospital discharge. Eur Respir J. (2020) 55:2001217. doi: 10.1183/13993003.01217-2020

32. Huang C, Wang Y, Li X, Ren L, Zhao J, Hu Y, et al. Clinical features of patients infected with 2019 novel coronavirus in Wuhan, China. Lancet. (2020) 395:497-506. doi: 10.1016/S0140-6736(20)30183-5

33. Gattinoni L, Chiumello D, Caironi P, Busana M, Romitti F, Brazzi L, et al. COVID-19 pneumonia: different respiratory treatments for different phenotypes? Intensive Care Med. (2020) 46:1099-102. doi: 10.1007/s00134-020-06033-2

34. Schaller T, Hirschbuhl K, Burkhardt K, Braun G, Trepel M, Markl B, et al. Postmortem examination of patients with COVID-19. JAMA. (2020) 323:2518-20. doi: 10.1001/jama.2020.8907
35. Carsana L, Sonzogni A, Nasr A, Rossi RS, Pellegrinelli A, Zerbi P, et al. Pulmonary post-mortem findings in a series of COVID-19 cases from northern Italy: a two-centre descriptive study. Lancet Infect Dis. (2020). doi: 10.1016/S1473-3099(20)30434-5. [Epub ahead of print].

36. Ackermann M, Verleden SE, Kuehnel M, Haverich A, Welte T, Laenger F, et al. Pulmonary vascular endothelialitis, thrombosis, and angiogenesis in Covid-19. N Engl J Med. (2020) 383:120-8. doi: 10.1056/NEJMoa2015432

37. Polak SB, Van Gool IC, Cohen D, von der Thusen JH, van Paassen J. A systematic review of pathological findings in COVID-19: a pathophysiological timeline and possible mechanisms of disease progression. Mod Pathol. (2020). doi: 10.1038/s41379-020-0603-3. [Epub ahead of print].

38. Copin MC, Parmentier E, Duburcq T, Poissy J, Mathieu D, Lille C-I, et al. Time to consider histologic pattern of lung injury to treat critically ill patients with COVID-19 infection. Intensive Care Med. (2020) 46:11246. doi: 10.1007/s00134-020-06057-8

39. Lederer DJ, Martinez FJ. Idiopathic pulmonary fibrosis. N Engl J Med. (2018) 378:1811-23. doi: 10.1056/NEJMra1705751

40. Solomon JJ, Fischer A. Connective tissue disease-associated interstitial lung disease: a focused review. J Intensive Care Med. (2015) 30:392400. doi: $10.1177 / 0885066613516579$

41. Pallett LJ, Schmidt N, Schurich A. T cell metabolism in chronic viral infection. Clin Exp Immunol. (2019) 197:143-52. doi: 10.1111/cei.13308

42. Tashiro J, Rubio GA, Limper AH, Williams K, Elliot SJ, Ninou I, et al. Exploring animal models that resemble idiopathic pulmonary fibrosis. Front Med. (2017) 4:118. doi: 10.3389/fmed.2017.00118

43. Forel JM, Guervilly C, Hraiech S, Voillet F, Thomas G, Somma C, et al. Type III procollagen is a reliable marker of ARDS-associated lung fibroproliferation. Intensive Care Med. (2015) 41:1-11. doi: 10.1007/s00134-014-3524-0

44. Liu T, Ullenbruch M, Young Choi Y, Yu H, Ding L, Xaubet A, et al. Telomerase and telomere length in pulmonary fibrosis. Am J Respir Cell Mol Biol. (2013) 49:260-8. doi: 10.1165/rcmb.2012-0514OC

45. Arish N, Petukhov D, Wallach-Dayan SB. The role of telomerase and telomeres in interstitial lung diseases: from molecules to clinical implications. Int J Mol Sci. (2019) 20:2996. doi: 10.3390/ijms20122996

46. Courtwright AM, El-Chemaly S. Telomeres in interstitial lung disease: the short and the long of it. Ann Am Thorac Soc. (2019) 16:17581. doi: 10.1513/AnnalsATS.201808-508CME

Conflict of Interest: SC received consulting and speaking fees from Boehringer Ingelheim, Genentech, and Veracyte. MG serves on the advisory board for Bellerophon Therapeutics.

The remaining authors declare that the research was conducted in the absence of any commercial or financial relationships that could be construed as a potential conflict of interest.

Copyright $\odot 2020$ Chaudhary, Natt, Bime, Knox and Glassberg. This is an openaccess article distributed under the terms of the Creative Commons Attribution License (CC BY). The use, distribution or reproduction in other forums is permitted, provided the original author(s) and the copyright owner(s) are credited and that the original publication in this journal is cited, in accordance with accepted academic practice. No use, distribution or reproduction is permitted which does not comply with these terms. 